\title{
Contribuições de teorias de vertente marxista para os estu- dos da linguagem
}

Ana Zandwais ${ }^{1}$

\begin{abstract}
The purpose of this article is to reflect on the notions of language, discourse and ideology, considering the studies of two authors. Valentin N. Volochinov who studied the relationships between the signs and ideology, and can be considered the precursor of the studies on ideology in the soviet context of the years 1920-30, and referred by Michel Pêcheux in his Lecture 'Remontemonos de Foucault a Spinoza' (1980). Michel Pêcheux, who studied, during the years 1968-1980 in France, the relationships between discourse and ideology by following some conceptions produced by L. Althusser (ideological formations) and Michel Foucault, but at the same time criticized some gaps let by them.
\end{abstract}

Key-words: discourse; language; ideology

Resumo: Este artigo tem como objetivo refletir acerca das noções de língua, discurso e ideologia, considerando estudos realizados por dois autores. Valentin N. Volochinov, que estudou as relações entre signo e ideologia e pode ser considerado precursor de tais estudos no contexto soviético dos anos 1920-30 e, inclusive, referido por Michel Pêcheux em sua Conferência 'Remontemos de Foucault a Spinoza' (1980). Michel Pêcheux, que estudou, durante os anos 1968-80, na França, as relações entre discurso e ideologia perseguindo algumas concepções produzidas por L. Althusser (formações ideológicas) e por Michel Foucault, mas que ao mesmo tempo criticou algumas lacunas deixadas por estes autores.

Palavras-Chave: discurso; língua/linguagem; ideologia

Se nos reportarmos às bases de fundação dos estudos da linguagem de vertente marxista, para além de Karl Marx (1986), que preconiza a linguagem como: a) o espaço onde as práticas sociais adquirem valores simbólicos, sendo a linguagem configurada pela condição de ter-se inaugurado a partir da necessidade de interação laboral para fins de produção; b) a consciência prática real que permite aos homens simbolizar as experiências vividas, transformando suas relações com os objetos e transformando-se, ao mesmo tempo; podemos constatar, através de um percurso retrospectivo, que alguns dos fundamentos mais importantes sobre as condições materiais do funcionamento da linguagem, de sua essência, de suas relações com os domínios histórico e dialético remontam ao contexto soviético. Mais precisamente, ao início do sec. XX (1920-1930), período dentro do qual podem ser tomadas como referências, fundamentalmente, duas obras: 'Marxismo e Filosofia da Linguagem² (1986) e 'Chto Takoe Yazik' ( O Que é a Língua e a Linguagem³) (2009).

1 Docente dos Cursos de Graduação e Pós-Graduação em Letras da Universidade Federal do Rio Grande do Sul.

2 Para fins da realização deste estudo em 'Marxismo e Filosofia da Linguagem' estamos trabalhando com a edição brasileira de Marxismo e Filosofia da Linguagem que data de 1986., traduzida do Francês, e que confere a autoria deste texto a Mikhail Bakhtin e Valentin Volochinov. No entanto, é preciso observar que as versões inglesa (1973) e russo-francesa (2009) atribuem a Valentim Volochinov a autoria de Marxismo e Filosofia da Linguagem.

3 O texto de Volochinov está sendo pesquisado, para fins deste estudo, nas versões francesa, de tradução de Patrick Sériot e Inna Tylkowski Ageeva (2009), e Portuguesa, traduzida por João Wanderlei Geraldi (2013). 
Partindo do pressuposto marxista de que a linguagem não é independente da realidade material, mas, ao mesmo tempo, necessita extrapolá-la, ultrapassar os fins imediatos aos quais ela serve, como meio de interação, como facilitadora da produção, meio de acesso às trocas de toda ordem, Bakhtin/Volochinov em 'Marxismo e Filosofia da Linguagem' (MFL:1986) e V.Volochinov em ‘Chto Takoe Yazik' (2009) irão tratar das condições em que a linguagem, para tornar-se um objeto simbólico, precisa ser explicada em termos de suas relações de mediação.

É a partir, pois, de uma perspectiva que busca investigar com base em pressupostos materialistas como a linguagem está a serviço de interesses contraditórios e de que modo as relações entre língua e ideologia se interpenetram, tornando possível explicar como a palavra se constitui no "ator principal" da arena social onde se travam as lutas de classe que Bakhtin/Volochinov em 'Marxismo e Filosofia da linguagem' (1986) elaboram dois capítulos que entendemos ser fundamentais, entre todos: a) um capítulo dedicado ao estudo das ideologias sob o âmbito da filosofia da linguagem; b) um capítulo dedicado às relações entre a infra-estrutura e as superestruturas.

Comecemos, então, pela leitura de algumas questões que entendemos ser imprenscindíveis no capítulo que trata, de modo específico, da ideologia.

Em sua teoria sobre o signo, Bakhtin/Volochinov (1986:31) refletem sobre como os objetos físicos, enquanto produtos de consumo, necessitam estar inscritos em uma ordem simbólica - a língua - a fim de que possam ultrapassar este plano e ser desinvestidos de seu valor imediato, isto é, o valor de produto meramente de consumo no seio social.

Esta função que não é meramente linguística e que o objeto linguístico desempenha, enquanto ordem simbólica, é que confere uma racionalidade ao signo, que, para além de ser cognitiva, está permeada por valores que traduzem as formas como as forças sociais se dividem em relação aos modos e meios de produção, permitindo compreender que o signo ideológico não pode ser "apenas um reflexo, uma sombra da realidade"(id.,p33), já que nem a realidade é diretamente acessada pelo valor imediato de um objeto de consumo - um corpo físico - nem a língua fora de suas relações de intersecção com fatos históricos e com a divisão das classes na disputa pelo poder e pela hegemonia de valores pode incorporar em seu interior o domínio do ideológico.

Mas Bakhtin/Volochinov, ao tratar do signo ideológico, conferem-lhe um espaço bem peculiar no interior de sua teoria, ao articularem, conforme Lähteenmäki (2012), o ideológico ao semiótico (znakouyi), com vistas a tratar do fato ideológico não apenas nos limites da linguagem verbal, mas para além dela, nos domínios da imagem, do gesto, do som, da cor, enfim das formas através das quais as diferentes massas físicas podem ser percebidas. Deste modo, se a condição essencial do signo ideológico é a de representação, de formas mediada, assimétrica e valorativa do real, através do simbólico, este trabalho de representação funciona de modo específico em diferentes esferas de 'criatividade ideológica'. Ou seja, os modos como os signos se inscrevem nos domínios do simbólico e da história nos domínios da arte, da literatura, por exemplo, seriam distintos da forma de inscrição dos signos nos domínios da filosofia, da ética ou das ciências biológicas, configurando, assim, formas específicas de relação objetiva entre os sentidos que os significantes adquirem no interior de uma ciência e os modos como as ciências são produzidas.

É preciso destacar que, segundo Bakhtin/Volochinov (1986:36), a palavra seria o signo mais indicativo do trabalho ideológico em virtude de seu funcionamento dialético. Sendo o material semiótico de expressão de todos e ao mesmo tempo um signo neutro, ela somente converte-se em signo ideológico ao incorporar os valores contraditórios dos que a utilizam, refletindo e refratando a ordem do real de formas distintas e até mesmo paradoxais. 
É importante também salientar que Bakhtin/Volochinov em (MFL) distinguem dois tipos de ideologia.

Na primeira acepção, a ideologia é tomada como Ciência dos signos (nauka ob ideologiiak), que permite compreender a atividade simbólica de representação e de produção dos sentidos nas diferentes esferas da sociedade, para além de uma atividade meramente lógico-formal. ${ }^{4}$ Esta é compreendida como uma ciência mestra que permite explicar como funcionam as diferentes formas de expressão semiótica da criatividade ideológica, remetendo, necessariamente, para relações históricas e dialéticas.

Na segunda acepção, a ideologia é tomada como visão de mundo, produzida no cotidiano da vida pelas forças sociais, independente do fato de que os sujeitos tenham consciência de sua existência como tal e de seus efeitos. Esta concepção remete às experiências vivenciadas de modo direto pelos sujeitos, independente do fato de que tais experiências possam ser mediatizadas ou interpretadas por meio de sua inscrição em uma ordem simbólico-histórica.

Torna-se importante ressaltar, por outro lado, que enquanto as experiências vividas e percebidas de forma mais imediata constituem a 'matéria prima' para os estudos desenvolvidos pela ideologia tomada como Ciência dos signos, é a própria ideologia enquanto ciência dos signos que viria a fornecer os pressupostos, ou seja, a "ação de retorno", conforme Lähteenmäki ( 2012: 96), do conhecimento acerca da experiência, do vivido, intervindo nas próprias condições de compreensão, pelas forças sociais, das atividades simbólicas do cotidiano.

Assim, se determinadas relações causais são refratadas na ordem do simbólico, no cotidiano da vida, o estudo das condições em que os sentidos se refletem e são refratados em diferentes contextos, em virtude dos interesses que dominam entre as classes, os grupos sociais, é desenvolvido pela ideologia, compreendida como uma ciência que busca explicar tanto as condições através das quais os sentidos se refratam, como o modo através do qual estes se relacionam de forma instável com os significantes a fim de preservar interesses de classe que são distintos.

Para Bakhtin/Volochinov (id,p.38), desta forma, uma Ciência das ideologias torna-se indispensável à compreensão tanto do modo de produção e hegemonia de determinados valores simbólicos em detrimento de outros, quanto dos processos de refração ideológica verbal que corresponderiam às próprias condições de refração ideológica dos sujeitos, alienados da compreensão de suas próprias práticas ou cerceados por suas condições existenciais.

Cabe observar, por outro lado, que tal relação dialética posta entre a ideologia como práxis imediata e como trabalho de representação de ordem simbólica e mediatizada é que permite a Bakhtin/Volochinov (1986) tratar da questão das relações entre infraestrutura e superestruturas e, sobretudo, das relações contraditórias entre ambas.

Partindo, inicialmente, da necessidade de explicar o trabalho da ideologia na infraestrutura, a partir do modo de determinação das condições históricas e das correlações de força com as superestruturas, Bakhtin/Volochinov (id.,p.40) observam que todos os fenômenos, as transformações que afetam as forças sociais não podem ser compreendidos senão a partir das próprias condições existenciais e de produção da infraestrutra, de tal forma que entender como os signos refletem e refratam a realidade na infraestrutura, a partir de determinadas condições históricas, seria diferente de entender como os signos refletem e refratam a realidade das superestruturas porque seus interesses são conflitantes.

4 Queremos aqui considerar, sem dúvida, a influência da obra de Ernst Cassirer 'A Filosofia das Formas Simbólicas' (2001) para a construção de uma teoria dos signos, mas também considerar o fato de que os estudos desenvolvidos por Cassirer tratam da representação sígnica de uma perspectiva dominantemente formal. 


\section{Conexão Letras}

Ao afirmar, deste modo, que "as palavras são tecidas a partir de uma multidão de fios ideológicos e servem de trama a todas as relações sociais em todos os domínios”(id.,p.41) Bakhtin/Volochinov estão tratando de diferenças qualitativas que dominam os modos de produção do simbólico, pelo viés da linguagem, mas que acabam por redundar em modos de produção e de refração de sentidos distintos. Sob o ponto de vista prático, podemos elucidar a questão, observando que o 'conteúdo' da História narrada pelo viés das superestruturas não coincide com o 'conteúdo' da História narrada pelas forças sociais, embora ambas venham a tratar dos mesmos objetos.

Esta relação, postulada a partir das categorias marxistas que permitem representar a tópica do funcionamento das esferas do político e que os autores inscrevem na ordem do simbólico, parece ser uma contribuição genuinamente materialista ${ }^{5}$, para além de uma leitura de Marx, na medida em que não só as correlações de forças materiais entre a infraestrutura e as esferas de poder superestrutural são representadas dialeticamente, mas também as correlações de força entre a ordem do simbólico e as formas de expressão das práticas sociais são colocadas sob o olhar da contradição.

Este modo de investigar a ordem do simbólico a partir de uma ciência (nauka ob ideologiiak) que estabelece relações intrincadas entre o trabalho do signo e o trabalho da ideologia, buscando centrar a observação em torno das "discrepâncias" entre as formas de ação e de expressão verbal do corpo social, permite também a Bakhtin/Volochinov refletir sobre os critérios que determinam a escolha de determinados temas em detrimento de outros, por uma ou outra classe, e, sobretudo, caracterizar o modo de produção dos gêneros discursivos a partir de condições que vêm responder aos conjuntos de interesses e aos valores dominantes no seio das diferentes classes e grupos sociais. Assim, as formas de constituição e de circulação dos enunciados que compõem os discursos produzidos em diferentes esferas de produção precisam ser tomadas como objetos de investigação a partir de circunstâncias concretas vivenciadas dentro das organizações sócio-políticas.

É importante salientar que para Bakhtin/Volochinov(1986) "cada época e cada grupo social tem seu repertório de formas discursivas", bem como a seleção de temas não é aleatória, mas responde integralmente aos interesses e às necessidades dos grupos sociais.

É a partir desta perspectiva, portanto, que, para que se possa compreender em que consiste um gênero discursivo é preciso entender que os gêneros não se constituem primeiramente na materialidade da língua, mas a partir do modo como os signos que compõem o repertório discursivo de cada classe, cada grupo social representam formas de produção e de segmentação sócio-política, refletindo, em última instância, o modo como as formas de expressão verbal incorporam valores e práticas de classe e materializam-se sob diferentes modalidades e 'acentos' discursivos.

O tema e a forma do signo ideológico, conforme Bakhtin/Volochinov(id.,p.45), "estão indissoluvelmente ligados", “... constituem duas facetas de uma só e mesma coisa." (id.,p.46) Assim, por exemplo, se uma campanha política do gênero panfletário ${ }^{6}$ coloca em pauta a necessidade de câmeras e de segurança nas ruas do centro e nos bairros de uma cidade populosa, este tema tem como destinatários principais as classes média e alta, não

5 É importante lembrar que 'Marxismo e Filosofia da Linguagem começou a circular na URRS em 1929 e que 'A Ideologia Alemã', obra em que Marx trata da questão ideológica somente entra em circulação em 1932.

6 Nos reportamos ao gênero panfletário, como um gênero de discurso político com fins essencialmente pragmáticos, para o qual importam o trabalho de massificação independente de razões lógicas, os meios tornam-se irrelevantes em favor dos resultados imediatos. Como um discurso que produz ecos a partir de sua força de persuasão por identificação com as condições de vida, com o lugar do outro. 
sendo tão relevante para as classes de baixo poder aquisitivo, já que estas não possuem bens altamente cobiçados como as demais classes. Mas, o tema, ao mesmo tempo em que coloca em destaque as questões de determinada classe, precisa garantir que o discurso panfletário produzido responda, de forma eficiente, às expectativas destas classes a fim de cumprir os objetivos pretendidos.

Do mesmo modo, a título de ilustração, uma campanha política que dá destaque à falta de empregos e à resolução de questões assistenciais aos trabalhadores que vivem na informalidade tem como destinatários as classes mais baixas, os que trabalham sem carteira de trabalho e sem direitos assistenciais e os desempregados. Os interesses que estão implicados neste gênero de discurso, portanto, podem ser assistencialistas, populistas, simplesmente eleitorais, mas, inegavelmente, precisam ser apresentados como contraditórios aos valores que sedimentam os interesses do lucro e da exclusão social.

$\mathrm{O}$ mesmo se pode dizer da seleção de registros. O emprego do registro vernacular e dos jargões metalingüísticos é próprio do uso das classes de nível sócio-cultural mais elevado, ao passo que o emprego dos jargões de alta produtividade falada é próprio dos grupos jovens e dos grupos menos reconhecidos socialmente como os grafiteiros, pichadores, sacoleiros, funkeiros, hip-hops, etc. Cada modalidade de registro, desta forma, tem seus "espaços" delimitados de reconhecimento mútuo, de inclusão, de exclusão e de resposta ao outro e ao meio social.

Portanto, a partir desta perspectiva, tanto as formas de estratificação social e funcional da língua como os gêneros discursivos derivam das relações de produção de uma sociedade, mas não de modo direto ou transparente. Daí a necessidade de se pensar sobre as relações entre o simbólico e o ideológico, já que toda diferença social é refletida em termos simbólicos e através de diferentes 'acentos discursivos' que colocam determinados valores regionais em perspectiva, mas retratando-os como se fossem universais.

E para tratar desta questão, duas noções tornam-se fundamentais nas obras de Volochinov ( 2009) e de Mikhail Bakhtin (1986-a). ${ }^{7}$ A noção de heteroglossia (raznoiaziche), que vem a ser definida pela condição de hibridez de toda língua, considerando-se que uma língua somente pode ser compreendida como um conjunto heterogêneo e estratificado de línguas que a constituem como um todo complexo, e cuja unidade se produz pela diferença.

A noção de heterofonia, (raznorechie), que se define pela condição de que um discurso é um todo multifacetado, não uno, porquanto, fragmentado em múltiplas vozes, múltiplas formas de responsividade que demandam sempre a inscrição de um discurso em outros discursos. Assim, tanto as formas de orientação do trabalho da língua (yazik), das palavras (slovo) que compõem os enunciados caracterizam a identidade semiótica de um discurso (rech) de um modo peculiar: são produzidas sob a hibridez, a fragmentação e a contradição.

É com base nesta ótica que, para Bakhtin/Volochinov (1986), os signos lingüísticos são orientados no interior da língua e, suas formas de discursividade podem ser metaforizadas pela imagem de uma arena onde se trava ' a competição ideológica.' Mas esta arena torna-se mais específica, por ser uma 'arena viva' e, ao mesmo tempo, porque é somente a partir de seu 'interior' que se pode refletir sobre a influência dos valores externos sobre os grupos sociais e suas formas de valoração.

É, pois, no âmbito desta lógica que, para Bakhtin/Volochinov (id.,p.45) "não se pode entrar no domínio da ideologia, tomar forma e aí deitar raízes senão naquilo que adquiriu um valor social.” Assim, para Bakhtin/Volochinov é através da língua, na medida em que

7 Fazemos referência, notadamente, ao texto de Volochinov 'Chto Takoe Yazik'[ Quest ce que la langue et le langage], publicado pela Edit. Lambert-Lucas, 2009 e ao texto ' The Problem of speech genres', publicado em 'Speech genres and other late essays', pela University of Texas Press, 1986, no qual Mikhail Bakhtin reflete sobre a noção de gênero discursivo. 


\title{
Conexão Letras
}

os sujeitos são capazes de preencher os valores que os signos adquirem como índices representativos e vivos dos valores sociais e culturais dos grupos, das classes que se pode compreender o funcionamento da contradição sob uma perspectiva dialética. Por fim, pode-se dizer que a língua viva, para Volochinov (2009), pode ser entendida como o todo de um conjunto de signos pluriacentuados e que expressam as posições ideológicas dos sujeitos em suas correlações de força nas diferentes esferas sociais.

Se nos reportarmos, por outro lado, ao contexto francês, e ao pensamento do filósofo Michel Pêcheux, na década de 1980, e, mais precisamente, ao texto "Remontémonos de Foucault à Spinoza”, encontramos uma ponte entre as reflexões marxistas já realizadas por Volochinov e a abertura da reflexão de Pêcheux em torno da língua, do materialismo e da ideologia através da referência que passamos a transcrever a seguir:

\begin{abstract}
"Lengua, ideologia y discurso: ni Marx, ni Lênin, ni ninguno de los llamados "clássicos del marxismo" produjo um estúdio organizado politicamente sobre este tema. De hecho, los pensadores politicos del marxismo leninismo se quedaron a esse respecto en obsevaciones de orden muy general (por exemplo, lo que se puede encontrar em Gramsci); de modo que desde Volochinov hasta nuestros dias puede decir-se que esta cuestión há sido y sigue siendo esencialmente cosa de universitários progressistas (pocos lingüistas, historiadores y filósofos sobre todo)." Pêcheux (1980:230)
\end{abstract}

Esta retomada de Pêcheux aos estudos realizados por Volochinov acerca do papel da língua, do signo e da ideologia, parece constituir-se em uma "âncora" fundamental, a partir da qual Pêcheux propõe-se a sustentar suas leituras marxistas-leninistas em torno da linguagem, da ideologia e dos sentidos.

Por outro lado, foi necessário a Pêcheux reconhecer, ao longo de sua trajetória de investigações $^{8}$ não somente os deslizes de seu percurso inicial, que privilegiou as bases de uma teoria distribucionalista como a de Zellig Harris (1973), para fundamentar sua noção de discurso, e a construção de métodos informacionais para a realização de análises, ${ }^{9}$ como também o fato de que tanto Karl Marx ( 2008) como V. Lênin ( 1986) não teriam tido cuidado suficiente para desenvolver reflexões em torno de questões de linguagem.

Seria, portanto, seria este o domínio de conhecimentos lacunar já explorado por Volochinov, durante os anos 1920-1930, sobre o qual Pêcheux iria também se debruçar. E a identidade entre ambos começa a se pautar pela busca de uma ciência capaz de investigar as questões de ordem simbólica como questões da ordem do ideológico.

Cabe acrescentar, por outro lado, o fato de que no contexto da Academia francesa os saberes marxistas, à exceção dos anos 1968-1970, não teriam grande relevância, de modo que Pêcheux viria a desenvolver suas investigações "fora de lugar", buscando construir uma disciplina cujos pressupostos epistemológicos fundamentais - o materialismo histórico e o materialismo dialético - tomados da obra de Marx, da obra de Lênin, dentre outras reflexões materialistas ${ }^{10}$, seriam considerados marginais, sobretudo, pelos lingüistas.

8 Fazemos referência, sobretudo, aos escritos produzidos durante a fase inicial de fundação da disciplina de 'Análise Automática do Discurso', que nos remete a uma proposta de hibridação entre pressupostos distribucionalistas de discurso e materialistas, acarretando um engessamento do próprio processo de construção de uma teoria materialista do discurso.

9 Reportamo-nos, notadamente, aos métodos inicialmente propostos para análises automáticas do discurso que fundamentaram-se em pesquisas alicerçadas em estudos estatísticos em torno do léxico e de discursos de temática política, criando a ilusão de que se poderia construir um dispositivo de análises discursivas a partir de métodos formalistas.

10 Queremos colocar aqui em destaque a obra de Benedictus Spinoza 'Tratado Político' (1994) produzida no sec. XVII e tomada como um marco referencial dos estudos materialistas. 
Esta questão parece, no entanto, estar bem clara para Michel Pêcheux, quando no texto Formação Social, Língua, Discurso" produzido juntamente com Catherine Fuchs (1975:163) são tecidas algumas considerações em torno de sua proposta de articular três regiões distintas do conhecimento como o Materialismo histórico, a Linguística e uma Teoria do discurso, no que se refere ao modo como a articulação entre estas regiões de conhecimento seriam recebidas pela Academia, conforme os comentários que transcrevemos a seguir:

"Observemos desde logo que, nas condições atuais do trabalho universitário, tudo concorre para tornar mais dificil a articulação teórica entre estas regiões. Além de esta articulação parecer a alguns de gosto teórico duvidoso, subsiste o fato de que, mesmo com a melhor vontade teórica e política do mundo, é dificil levantar os obstáculos ligados à balcanização dos conhecimentos e sobretudo ao recalcamento-mascaramento universitário do materialismo histórico." (1990: 165)

Dentro deste contexto impróprio à produção de uma Teoria discursiva de base materialista, foi essencial para Pêcheux explorar algumas questões teóricas e analíticas propostas por outros pensadores, como as reflexões em torno do simbólico e do ideológico, propostas por Volochinov, mas também rejeitadas dentro do contexto soviético ${ }^{11}$.

Mas M. Pêcheux tomou também determinadas concepções de outros filósofos franceses, dentre as quais destacamos os conceitos formulados por Michel Foucault em 'Arqueologia do Saber' (2000) e os conceitos formulados por Louis Althusser em 'A Reprodução' (1999), a fim de que ele pudesse levar adiante sua proposição de articular três regiões distintas do conhecimento para constituir sua teoria.

Comecemos por compreender os tipos de relações que ele considerou necessárias entre o materialismo histórico, a Linguística e uma Teoria do discurso.

Buscando também, como Volochinov, construir uma teoria que pudesse tratar do funcionamento da ideologia, enquanto 'uma superestrutura ideológica em sua ligação que domina o modo de produção de uma formação social considerada' (1990:165) Pêcheux irá tentar superar as investigações de tipo marxista mecanicista que estabelecem pontos de contato direto entre a base econômica e as ideologias, à semelhança de Volochinov, que denunciava a força das idéias positivistas e formalistas nos domínios dos estudos materialistas sobre a linguagem, no contexto dos anos 1920-30, mas por caminhos que podem ser considerados diferentes.

Enquanto Volochinov tentou ultrapassar o olhar mecanicista de seus contemporâneos que pensavam as relações entre os estudos da linguagem e o modo de produção da base econômica como imediatamente articulados, permitindo o acesso direto às formas de produção dos sentidos na linguagem, através da construção de uma teoria do signo ideológico, em que a questão do valor é posta como eixo central, mas não transparente do trabalho simbólico, Michel Pêcheux (1990), com base em uma crítica em torno da perspectiva mecanicista de ideologia ${ }^{12}$ hegeliana irá configurar o papel da ideologia em diferentes instâncias, partindo do que ele denomina de 'modalidade particular de funcionamento da instância

11 É importante salientar que 'Marxismo e Filosofia da Linguagem', ainda que tenha gerado muitas discussões entre os lingüistas soviéticos, saiu 'fora de circulação' tendo as idéias de Volochinov em torno do signo e de sua condição dialética sido resgatadas , conforme Lähtheenmäki, somente na década de 1970 por Viacheslav V. Ivanov.

12 Transcrevemos a seguir alguns comentários de Pêcheux (1990:165) sobre a questão: “Os trabalhos marxistas recentes mostram a insuficiência de considerar a superestrutura ideológica como expressão da "base econômica", como se a ideologia fosse constituída pela "esfera das idéias", acima do mundo das coisas, dos fatos econômicos, etc. 
ideológica quanto à reprodução das relações de produção' (id.,p.165) e que caracteriza como sendo um processo complexo que envolve tanto uma análise do modo de produção econômica, da divisão do trabalho, do funcionamento dos aparelhos de Estado como do modo de interpelação ou assujeitamento do sujeito em sujeito ideológico, conceitos estes tomados de L. Althusser (1999).

Para Pêcheux (1990), que se ancorou em pressupostos althusserianos, mas também de modo diferente de Althusser (1999), na medida em que este conferiu às ideologias um papel determinante no seio das formas de organização institucional, elaborar uma teoria discursiva, em primeiro lugar, conferindo às ideologias um papel superestrutural implicava não somente libertar-se de uma leitura sobre a condição da ideologia como uma "questão metafísica" à moda hegeliana mas sobretudo articular as questões de práxis observadas por Althusser no seio dos aparelhos de Estado às suas formas simbólicas de expressão. Assim, podemos dizer que com Althusser a ideologia deixaria de ser representada de forma metafísica, ou como pura ilusão, como sonho e, portanto, avessa ao real. E este 'espaço' empírico' conferido à noção de ideologia interessava, sobremaneira, a Pêcheux.

Para Althusser, investigar os domínios do ideológico, implicava mostrar que as ideologias têm histórias próprias, concretas, e que podem somente ser compreendidas no plano das condições empíricas de existência, dos modos de produção dos sujeitos, a partir dos interesses que os movem segundo as formações sociais e as formações ideológicas com as quais estes se identificam e em que se inscrevem. É, pois, a partir do percurso de Althusser, cujo mérito, em primeiro lugar, consistiu em conferir à noção de formação ideológica um estatuto concreto, empírico, constituído no seio das instituições, que Pêcheux irá encontrar os alicerces sobre os quais irá assentar a noção de formação discursiva.

A designação, formação discursiva, proposta inicialmente por Michel Foucault (2000), em 'Arqueologia do Saber' (1987:26), trata da noção de unidade discursiva para chegar ao conceito de formação discursiva (Fd), e questiona se a unidade discursiva seria homogênea e "aplicável" de modo uniforme. Para responder que a unidade material de um discurso é somente aparente, e, portanto, efeito de dispersão, Foucault (1987:43) observa que os conjuntos de enunciados que compõem as unidades discursivas construiriam uma espécie de arquitetura, articulando, ao mesmo tempo, conceitos distintos, temas conflitantes, posições assimétricas e construções lingüísticas irregulares, que possibilitando o esboço de quadros de diferenças permitiriam descrever o modo de funcionamento dos sistemas de dispersão. É a partir deste trabalho de 'desmanche' da ilusão de unidade de um texto, que, para Foucault, todo discurso estaria preso a um sistema de remissões a outros discursos e a um sistema de dispersões como um "nó em uma rede." (id.p.26)

Michel Pêcheux, instigado pela noção não positivista de formação discursiva, proposta por M. Foucault ${ }^{13}$ irá, por sua ótica, servir-se das noções de dispersão e de heterogeneidade, com vistas à construção de uma noção própria de formação discursiva, marcada também pela heterogeneidade, mas articulada à noção althusseriana de formação ideológica, a fim de poder caracterizar, de modo concreto, como as ideologias se constituem e tomam forma como práticas e discursos simultaneamente, constituindo as formações imaginárias dos sujeitos e produzindo efeitos de universalidade, que ao se naturalizarem parecem compor a própria 'ordem do real'.

13 É importante observar que Michel Foucault, ao ministrar a disciplina 'História dos Sistemas de Pensamento no 'Collège de France' desenvolveu através de seus Seminários reflexões de diferentes ordens sobre o objeto discursivo, iniciando por 'Dits et écrits' (1994), 'A Ordem do discurso' ( 1987) e 'Arqueologia do Saber' (2000), através das quais passou a questionar a influência de pressupostos positivistas, no contexto francês, sobre o desenvolvimento de concepções discursivas. 
Faz-se necessário acrescentar também que um dos méritos de Louis Althusser consiste em refletir sobre o fato de que as questões ideológicas não poderiam ser discutidas somente com base em análises do papel da infra-estrutura econômica, mas necessitavam, sobretudo, ser investigadas em relação ao papel das forças políticas no seio do aparelho estatal, de suas formas de organização e de fragmentação, buscando caracterizar o funcionamento da ideologia no próprio no interior dos aparelhos políticos, enquanto instituições a serviço da ação política do Estado, ou seja, de suas formas concretas de materialização .

É preciso salientar, no entanto, que a noção de formação discursiva tal qual é elaborada por M. Pêcheux, não vem a se constituir em um acréscimo à teoria althusseriana; pelo contrário, esta noção torna-se fundamental por tratar de um aspecto lacunar na teoria de Althusser. Isto é, M. Pêcheux entende ser imprescindível investigar o funcionamento da ordem simbólica para poder tratar das diferentes formas de expressão da ideologia no seio dos aparelhos políticos: nos domínios das práticas e dos discursos, e, sobretudo, entrecruzando ambos.

Assim, a noção althusseriana de formação ideológica adquire uma importância ímpar, na medida em que é ela que irá conferir à própria noção de ideologia um estatuto concreto, sedimentado a partir da reflexão sobre o modo como as classes se relacionam, atuam, estabelecem correlações de forças no seio dos aparelhos institucionais de Estado, e é através desta noção que Althusser irá caracterizar como se produzem e se reproduzem as diferentes formas de manutenção/ massificação das relações de produção dominantes no seio dos aparelhos de Estado.

Com Pêcheux, por outro lado, a noção de formação discursiva irá configurar-se como um dos aspectos "materiais das materialidades ideológicas" (1990:166) que interligadas, no seio dos aparelhos promovem, ao mesmo tempo, e de forma tensa, as relações de reprodução e de transformação destes aparelhos. Em outras palavras, os aparelhos ideológicos passam a encarnar o "palco" onde as lutas e as contradições de classe se desenvolvem, mas não somente para a observação das relações de produção/reprodução das práticas institucionais, e sim para a observação do real das correlações de força no seio dos aparelhos que acaba por desencadear a transformação.

Podemos dizer que se a contribuição de Althusser torna-se fundamental para Pêcheux, caracterizando como a ideologia trabalha no interior dos aparelhos de repressão de Estado (a polícia, o exército, as prisões) e no interior dos aparelhos ideológicos propriamente ditos, onde o trabalho ideológico é assegurado por meio de um tipo de violência menos visível: a violência simbólica, é Michel Pêcheux que vem a aprofundar a questão da invisibilidade da violência simbólica justamente através da noção de formação discursiva.

Assim, de acordo com M. Pêcheux, as formações discursivas, por seu turno, permitem caracterizar as formas de inscrição e de reconhecimento dos sujeitos no interior dos aparelhos através da ordem simbólica - investigadas a partir de uma relação dialética entre o discurso, tomado como processo e uma base sobre o qual ele se articula. Vejamos como ele se coloca em relação à questão.

“....toda prática discursiva está, sobretudo, inscrita no complexo contraditório-desigual-sobredeterminado das formações discursivas, o que vem a caracterizar a materialidade da instância ideológica por condições históricas reflexas nas práticas discursivas, sendo necessário subtrair-se dessa relação a homogeneidade, a transparência e a circularidade dos efeitos da prática política no campo discursivo." Michel Pêcheux (1988:213)

A citação acima, que busca caracterizar as práticas discursivas como formas de concretização do político, ou seja, da ação da ideologia sobre as forças sociais, adquire relevância 
especial na medida em que, tais práticas, enquanto materialidades da instância ideológica não são homogêneas, transparentes ou circulares, devendo ser, portanto, observadas nas contingências em que se produzem.

Eis porque Pêcheux precisa distinguir as materialidades da língua e do discurso, já que as primeiras agem como uma base comum, reproduzem-se, enquanto o discurso necessita ancorar-se nas determinações históricas, nas contingências que desafiam a ordem do repetível, nas correlações de força sociais, constituindo um espectro bem mais complexo e menos transparente do que os domínios lingüísticos, cuja autonomia passa a ser entendida, sob este prisma, como sendo relativa, por produzir efeitos semânticos somente a partir de sua inscrição nos domínios discursivos.

Do mesmo modo, é importante dar destaque, seguindo o percurso de Althusser e, ao mesmo tempo, à forma como M. Pêcheux lê Althusser, à noção de interpelação do indivíduo em sujeito ideológico. Para Pêcheux interessa, inicialmente, o modo como L. Althusser descreve o "livre assujeitamento do indivíduo" como uma condição constitutiva do sujeito e ao mesmo tempo imaginária. ${ }^{14}$

Seguindo as pegadas de Althusser, Pêcheux irá tratar também do processo de assujeitamento, sendo este configurado como um processo "de tal modo que cada um seja conduzido, sem se dar conta, e tendo a impressão de estar exercendo sua livre vontade, a ocupar o seu lugar em uma ou outra" formação social, identificando-se ao seu modo de produção.

A perspectiva de assujeitamento Pêcheux, no entanto, precisa ser deslocada a partir da constatação de que as formações discursivas são heterogêneas em sua composição e mantêm entre si relações dissimétricas, de modo a constituir um trabalho de reconfiguração incessante.

Esta perspectiva leva Pêcheux a deslocar o centro de "racionalidade" da teoria althusseriana para outro lugar; isto é, ao propor que o trabalho incessante de reconfiguração das Fds. é uma conseqüência do fato de que a relação entre as formações ideológicas (FIds) e formações discursivas (Fds) não é estável, nem a reprodução das relações de produção se opõe às relações de transformação, ele passa a questionar as bases do próprio modo de sedimentação das ideologias no interior dos aparelhos de Estado.

Ao questionar, portanto, a condição de circularidade da reprodução a fim de explicar como se produz o processo de alienação que sedimenta as condições de hegemonia dos valores de determinadas classes de posse dos aparelhos de Estado, ele precisa também questionar as hipóteses que caracterizam o "voluntarismo pleno" no processo de assujeitamento ideológico dos sujeitos proposto por Althusser. Para Pêcheux, é certo que os processos discursivos não têm sua origem nos sujeitos, mas se realizam através dos sujeitos, mas de um modo bem mais complexo que transcende a idéia de voluntarismo pleno, e que ele passa a designar como 'o bom sujeito'.

Assim, em virtude do fato de estarem atrelados a condições de produção distintas, determinadas pela história e pelos acontecimentos, os processos discursivos se reformulam, são ressemantizados, produzindo determinados efeitos que tornam mais complexas e heterogêneas as formações discursivas nas quais os sujeitos se reconhecem, e, sobretudo os modos através dos quais os indivíduos podem se reconhecer como sujeitos.

Desta forma, ainda que para Pêcheux, seja possível explicar, a partir das noções de interpelação e de aparelhos ideológicos de Estado de Althusser (1999), o que determina as relações de produção/reprodução de classe, econômicas, culturais e sociais, materialmente configuradas pelo modo como os aparelhos ideológicos de Estado agem sobre os

14 É importante ressaltar que a concepção de imaginário althusseriana não se opõe ao real, mas está fundada nas determinações históricas que afetam as condições de existência dos sujeitos. 
sujeitos, colocando em jogo práticas associadas a lugares que permitem compreender como se cristalizam os interesses e se produzem as relações de reprodução no seio da luta de classes, a teoria de Althusser parece ainda deixar lacunar leituras sobre o funcionamento da contradição no seio dos aparelhos ideológicos. É, pois, justamente este aspecto que Pêcheux passa a questionar.

É, portanto, a partir da dialética entre relações de reprodução/transformação no seio dos aparelhos ideológicos de Estado, e das formas de emergência dos saberes, e de seus modos de cristalização, de circulação e de transformação nas práticas discursivas que representam os interesses das formações ideológicas (FIds.) que Pêcheux irá produzir uma releitura da teoria de L. Althusser, buscando colocar em relevo o fato de que não haveria qualquer relação opositiva entre reprodução e contradição, já que ambas podem ocorrer simultaneamente e de formas tensas no interior dos aparelhos de estado, acarretando a reprodução, mas também a transformação das relações de produção.

Por outro lado, se nos propusermos a acompanhar o desenrolar da trajetória de Pêcheux em relação ao modo como ele produz uma teoria de base marxista, a partir de uma articulação de três regiões do conhecimento é preciso também que analisemos qual o estatuto a ser ocupado pela língua em sua relação com o objeto discursivo, com a história e com pressupostos dialéticos que viriam a desafiar as concepções positivistas de língua dominantes em diferentes épocas ${ }^{15}$.

Refletindo em torno da falta de "uma teoria do funcionamento material da língua em sua relação consigo própria" Pêcheux (1975:173) busca tratá-la em termos de sistematicidade, desde que esta não se oponha ao "não-sistemático"- a divisão língua/fala e que possa ser articulada sob os aspectos morfológico e sintático.

Entendendo que a caracterização da materialidade da língua seria uma questão nuclear para o analista de discurso, mas que, ao mesmo tempo, a descrição do funcionamento desta materialidade não poderia ser autônomo, considerando, sobretudo, o fato de que os sentidos não são dados pela língua, embora esta seja a matéria prima para a produção destes, Pêcheux opta por configurar a língua como a base material dos processos discursivos. Esta escolha coloca em perspectiva o fato de que a língua se constitui no lugar material que serve de alicerce para o funcionamento dos processos discursivos e que, enquanto "conteúdo simbólico" é universal - mesma para todos - mas enquanto "conteúdo de outro conteúdo" ou "corpo de outro corpo" ela possui autonomia relativa, já que seu funcionamento, no que tange aos efeitos semânticos que as estruturas morfológicas, sintáticas produzem é determinado por uma exterioridade.

Deste modo, ao conferir à língua uma autonomia relativa, conceito tomado de Althusser e redimensionado, a língua não pode realizar uma mediação direta entre o sujeito e o mundo, sendo apenas condição necessária mas não suficiente para estruturar o sujeito e

Produzir sentidos.

É, portanto, a partir da inscrição da língua em uma determinada região ideológica, mobilizada a partir do trabalho do interdiscurso que ela passa a significar. Desde esta perspectiva, a distinção entre base linguística e processo discursivo e suas relações com a ideologia consiste em uma tentativa, proposta por Pêcheux, de articular aos domínios de concretização e funcionamento das ideologias materialidades de naturezas distintas:

15 É preciso dar destaque ao fato de que as correntes lingüísticas que se tornaram mais notáveis em diferentes momentos históricos e em diferentes contextos, tanto do "Leste" como do "Oeste" foram as concepções positivistas. No final do sec. xix e início do sec. $\mathrm{xx}$ temos as concepções comparatistas no contexto do Leste europeu e no início do sec. xx, por exemplo, temos as concepções estruturalistas dominando o cenário do oeste europeu. 
a) a materialidade linguística, da ordem do sistemático, do logicamente estabilizado, da ordem do "funcionamento da língua em relação a si mesma";

b) a materialidade do discursivo, que não se submete a leis internas - sistêmicas sendo, portanto, qualificada como processo por produzir efeitos a partir de uma relação dissimétrica entre a estabilidade da língua e as contingências dos acontecimentos.

\section{Para Concluir}

Este artigo buscou investigar como as noções de língua, de discurso e de ideologia adquirem determinadas especificidades em dois contextos distintos. Primeiramente, focalizamos as concepções materialistas de Valentin Volochinov, as relações estabelecidas por este autor entre língua e ideologia e o modo como ele nos apresenta o funcionamento da ideologia no contexto soviético dos anos 1920-30, buscando caracterizar a ideologia tanto da perspectiva de uma ciência que se debruça sobre as práticas discursivas produzidas na infraestrutura como da perspectiva das práticas dentro das quais ela funciona, de modo independente da consciência que os sujeitos tenham dela. No contexto francês dos anos 1960-1970, buscamos refletir sobre as concepções de discurso e de ideologia propostas por Michel Pêcheux, acompanhando sua trajetória epistemológica e as formas de intervenção próprias na concepção de ideologia de L. Althusser e na concepção de formação discursiva de Michel Pêcheux. Com base na realização deste estudo, podemos concluir, de modo provisório, que não somente as incursões de M. Pêcheux pelas concepções de L. Althusser e de Michel Foucault influenciaram o modo de produção da disciplina de Análise do Discurso, mas também as leituras realizadas em torno das contribuições de V.Valentin Volochinov, em torno da relação dialética entre o estatuto da língua - a mesma para todos - e do discurso (rech), cujos sentidos não podem ser apreendidos de forma direta, sem a inscrição deste em um contexto sócio-histórico caracterizado pela correlação de forças entre os interesses super e infraestruturais.

\section{Referências}

ALTHUSSER, Louis. Sobre a reprodução. Rio de Janeiro: Ed. Vozes, 1999. Trad. Guilherme João de Freitas Teixeira

BAKHTIN, Mikhail (VOLOCHINOV, V.) Marxismo e filosofia da linguagem. Problemas fundamentais do método sociológico na ciência da linguagem. São Paulo: Ed. Hucitec, 1986. Trad. Michel Lahud, Yara Frateschi et al.

. Speech genres and other late essays. Austin: University of Texas Press, 1996

Translated by Vern W. McGee

FOUCAULT, Michel. Dits et écrits. Paris: Ed. Gallimard, 1994. . El orden del discurso. Barcelona, Ed. Tusques, 1987.

. A ordem do discurso. São Paulo: Ed. Loyola, 1996 Trad. Laura Fraga de Almeida Sampaio

. A arqueologia do saber. Rio de Janeiro: Ed. Forense Universitária, 2000. Trad.

Luiz Felipe Baeta Neves

LÊNIN, V. I. Obras escolhidas. São Paulo: Ed. Alfa-Omega, 1986. Trad. Instituto de

Marxismo-leninismo

LÄTHEENMÄKI, Mika. Valentin Voloshinov: signos, ideologia e sentido. In: História 
das idéias: diálogos entre linguagem, cultura e história. ZANDWAIS, A. (org.), Passo Fundo, Ed. UPF, 2012, p.92-119.

MARX, Karl, ENGELS, F. A ideologia alemã. São Paulo: Ed. Martins Fontes, 2008 Trad. Luis Claudio de Castro e Costa PÊCHEUX, Michel. Remontémonos de Foucault a Spinoza. El discurso político. TOLEDO, Mario Montforte (org.), México, UNAM, Ed. Nueva Imagen,1980, p.181-231. . Análise automática do discurso. In: GADET, F. e HAK, T. Por uma análise automática do discurso. Uma introdução à obra de Michel Pêcheux. Campinas: Ed. da Unicamp, 1990 Trad. Eni Pulcinelli Orlandi . FUCHS, Catherine. A propósito da análise automática do discurso: atualização e perspectivas (1975) In: Por uma análise automática do discurso. Uma introdução à obra de Michel Pêcheux. Campinas, Ed. da Unicamp, 1990 Trad. Péricles Cunha . Semântica e discurso: uma crítica à afirmação do óbvio. Campinas: Ed. da Unicamp, 1988. Trad. Eni Pulcinelli Orlandi et al.

SPINOZA, Benedictus de. Tratado político. São Paulo: Ed. Ícone, 1994. Trad. Norberto de Paula Lima

VOLOSHINOV, Valentin N. Marxisme et philosophie du langage. Les problèmes fondamentaux de la méthode sociologique dans la science du langage. Limoges, Ed. Lambert-Lucas, 2009 Traduit par Patrick Sériot et Inna Tylkowski Ageeva . Q'est-ce que la langue et le langage. In: Marxisme et philosophie du langage. Les problèmes fondamentaux de la methode sociologique dans la science du langage. Limoges: Ed. Lambert-Lucas, 2009, p.521-572

ZANDWAIS, Ana. Perspectivas da análise do discurso fundada por Michel Pêcheux na França: uma retomada de percurso.Santa Maria: Programa de Pós-Graduação em Letras, 2009 (Série Cogitare) 